\title{
Ensayo
}

\section{Una "vuelta breve" a la participación política digital y el acontecimiento mediático en las ideas de Sergio Roncallo-Dow}

\section{Ana María Córdoba-Hernández ${ }^{1}$ José Manuel Robles-Morales²}

DOI: 10.5294/pacla.2020.23.s.7

\section{Para citar este ensayo / to reference this essay / para citar este ensaio}

Córdoba-Hernández, A. M. y Robles-Morales, J. M. (2020). Una "vuelta breve" a la participación política digital y el acontecimiento mediático en las ideas de Sergio Roncallo-Dow. Palabra Clave, 23(supl.), e23s7. https://doi.org/10.5294/pacla.2020.23.s.7

\section{Resumen}

Este ensayo es parte de un homenaje a la figura de nuestro querido compañero Sergio Roncallo-Dow. Al ser este un trabajo compartido, nuestro cometido es volver a hablar con él, en su ausencia y a través de sus textos, sobre algunas cuestiones que nos interesaron a ambos y sobre las que compartimos largo con él, durante sesiones de discusión, no siempre en horas de oficina. En concreto, nos ha interesado rescatar aquí dos ideas, por una parte, los medios digitales y la participación política y, por otra, el acontecimiento. Para reproducir nuestras conversaciones, hemos optado por introducir primero lo que Sergio pensaba sobre estos temas y, a continuación, incluir algunas de las ideas con las que nos enfrentábamos cariñosamente a su forma de pensar. Todo ello, naturalmente, en un intento de

\footnotetext{
https://orcid.org/0000-0002-4752-9724. Universidad de La Sabana, Colombia. ana.cordoba@unisabana.edu.co

https://orcid.org/0000-0003-1092-3864. Universidad Complutense de Madrid, España.jmrobles@ucm.es
} 
seducir al lector para que se adentre en los problemas científicos que interesaban a Sergio y, al mismo tiempo, para no quedarnos con ese áspero y terrible sabor de boca del que sabe que la última conversación con él fue realmente la última.

\section{Palabras clave}

Acontecimiento mediático; redes sociales; participación política; espacio público; espacio digital. 


\section{El espacio público y el espacio digital: ¿de verdad no se ha ido todo por la alcantarilla?}

Para los que tuvimos la suerte, y me atrevería a decir, el privilegio de vivir cerca de Sergio Roncallo-Dow en estos últimos años, un simple café con él, a las 10:00 a. m., en eso que en nuestro argot solíamos denominar "tiempos de calidad", se convertía en una puerta abierta a un universo de curiosidades y juegos mentales. En su mundo, las posibilidades de análisis y de investigación de la buena brotaban sin dificultad de algo tan simple como el meme viral de Batman slaps Robin, el de Woman yelling at a cat, el balance anual de los hashtags más populares en Twitter en reemplazo del icónico almanaque mundial de nuestros tiempos o la viralización efímera de la fotografía de Aylan Kurdi. Lo mejor de esos cafés matutinos o vespertinos era que terminaban indefectiblemente con la tranquilizadora y célebre frase roncallesca que muchos sin duda recordarán: "No te preocupes, esa vuelta es breve".

¿Breve? Hoy se lo queremos preguntar de nuevo. ¿Por qué veía tan breve cada uno de esos análisis en los que los interlocutores nos devanábamos los sesos intentando seguirle el paso en sus idas y venidas, pasando por los laberintos mentales de Platón, McLuhan, Scolari, Benjamin, Deleuze o Kant, por citar solo los que primero se vienen a la cabeza?

Quizá solo ahora, que volvemos a repasar toda su obra, entendemos lo que pasaba. Sergio la tenía clara. Para él, y en esto siempre estuvimos de acuerdo, los medios digitales no podían pensarse de manera simplista como meras plataformas de flujos inocuos de información, sino que se convertían en nuevas formas, tanto de producción de sentido como de actuación de los usuarios. Veámoslo con más detenimiento.

En primer lugar, siguiendo a Scolari (2014), su gran colega y amigo: no se puede sostener que Twitter, Instagram o Facebook no mediaticen la comunicación, ni se puede decir que sean interfaces neutras a modo de simples arcaduces por los que llega un mensaje sin alterarlo. Por el contrario,

lo que tiene lugar aquí es un modo diverso de acercamiento a las formas en las que circulan los regímenes semióticos: los signos alcanzan 
otro tipo de movimientos que no pueden pensarse como desmetiatizados y que suponen, por el contrario, otro tipo de sintaxis mental, otras formas de operación en las que la velocidad genera nuevas dinámicas de producción de sentido. (Roncallo-Dow, 2015, p. 307)

Ahora bien, ¿qué pasa con el impacto directo en la actuación de la audiencia? Para Sergio, se puede pensar en cómo los medios digitales transforman el modo en que habitamos el tiempo y el espacio, y desde ahí alteran las maneras de pensar, entre otros, lo político. En este punto, Sergio siempre fue muy cauteloso de no caer en el extremo de los optimistas, ni en el de los pesimistas. Hasta el punto de que se atrevió a plantarle cara a la visión de la pérdida de lo político de Han (2014b) cuando afirma que en los blogs o las redes sociales que hoy en día construyen o reemplazan el espacio público no se produce ningún discurso:

No se construye espacio público alguno. Los medios digitales hacen que la sociedad se vuelva cada vez más pobre en su discurso. Impiden la construcción de una comunidad en un sentido empático. Solo producen al azar muchedumbres o multitudes de individuos aislados, de ego, sin cohesión alguna, sin lugar de discurso. El individuo ya no es una entidad política capaz de producir un nosotros. (p. 48)

Sin embargo, en este punto, se aleja prudentemente del filósofo surcoreano. Es verdad, Sergio reconoce que es posible que la performance — propia de las redes sociales — haya sustituido la participación, que la memoria política de las generaciones precedentes esté siendo reemplazada por unos flujos de apropiación cada vez menos estables, que los signos que circulan en las redes y las causas vayan a la velocidad del hashtag y que la memoria quede en los archivos que, posiblemente, nunca serán revisitados. Con todo, también reconoce, sin caer en el optimismo de un Castells (2012), que desde el hashtag se pueden producir efectos sobre lo real y que no es el soporte lo que da lugar a la performatividad, sino los modos en los que los signos se ponen a circular (Roncallo-Dow, 2015). En definitiva, la shitstorm ${ }^{3}$ de Han (2014a) podría tener, a su entender, un efecto performativo.

3 "Esta es una definición que ha circulado en internet y sus páginas de humor hace mucho tiempo. Aclara Raúl Gabás, traductor del texto de Han (2014): “Shitstorm significa, literalmente, 'tormenta de mierda'. Se usa en el sentido de tormenta de indignación en un medio de internet”. En http://www.urbandictionary.com/ la noción tratada por Han se acerca a la quinta acepción de esa palabra que la define como "una discusión acerca de algo sin sentido e inocuo que se sale de control y que consiste en una pelea acerca de nada”' (Roncallo-Dow y Mazorra-Correa, 2015, p. 127). 
En el planteamiento anterior, Sergio reconoce que las apuestas politicas de hoy pueden pasar por lo efímero, se viven en la inmediatez del presente, y es ahí donde generan las acciones, en contraposición a la noción de memoria política tradicional. Sin embargo, esto no puede llevar a decretar la muerte de la deliberación pública, como no se puede decretar la muerte del libro, ni de la lectura lineal que llega de la mano de kindle y los textos digitales.

En el ecosistema político, pasa igual que en el mediático. Las formas convencionales de participación conviven con las nuevas formas digitales. En la génesis de internet, se llegó a pensar que la red favorecería la relación entre representantes y representados, y que ejercería un efecto positivo sobre la profundización democrática (Hague \& Loader, 1999). Sin embargo, luego vinieron autores menos optimistas quienes afirmaron que el impacto de la red en política era relativo; una discusión en la que no terminan de ponerse de acuerdo, pues algunos consideran que solo son políticas aquellas acciones tradicionales en las que se requiere un compromiso identitario mayor por parte de los ciudadanos y otros consideran que las acciones políticas están evolucionando y encontrando otras formas de materialización. En este caso, y en eso concordamos con Sergio, a las formas de acción política les pasa lo mismo que al ecosistema de medios, pues

es necesario pensar que las especies mediáticas de antaño conviven
con nuevas especies que evolucionan y, consecuentemente, con nue-
vas formas de agonismo. Este es el sentido de pensar los medios,
como nos lo enseñara McLuhan, en términos de ambientes y no de
contenedores. No creo que la convivencia entre las especies mediá-
ticas sea predatoria, pienso que toda evolución mediática se puede
pensar en medio de las tétradas que nos dejó el viejo profesor cana-
diense, en continuo movimiento. (Roncallo-Dow, 2015, pp. 309-310)

En alguna ocasión, tuvimos la oportunidad de discutir con Sergio algunas de sus premisas sobre este tema. En concreto, esa idea suya, muy inspirada por McLuhan, de que estamos en un contexto de ambientes comunicativos que viven y conviven con sus propias dinámicas y procesos. Le argumentábamos que la velocidad, propia del sistema mediático digital, es un riesgo sobre los principios de argumentación y racionalidad que deben, al menos normativamente, regir el espacio público. Si él se basaba en McLuhan, nosotros en Habermas (2010), y si para criticar el sistema él se basaba en Han, nosotros en Virilio. 
Virilio (1986) nos alerta sobre el impacto negativo que tiene la velocidad de la tecnología en el campo de la política. El gran legado del autor es su idea del tiempo accidental. Hasta la irrupción masiva de las tecnologías digitales y de los medios globales y virales, hubo dos tiempos. Por un lado, teníamos el tiempo a largo plazo, es decir, la historia que se preocupa por los procesos y la estructura de las sociedades. Por otro lado, teníamos el tiempo de los eventos. Es decir, esos hechos que podemos llamar históricos por su importancia y alcance social, político o económico.

Sin embargo, el tiempo accidental, dice Virilio (1986), es un instante que no participa ni en el pasado (está descontextualizado) ni en el futuro (desaparecerá en poco tiempo). Un tiempo en el que viven los usuarios de Snapchat y que se rige por la tasa de accidentes del presente más inmediato. La velocidad es el movimiento fundamental del tiempo accidental y las tecnologías digitales son el arma que hace que este movimiento sea efectivo.

El corolario del argumento de Virilio (1986) es que, al entender nuestras vidas como un tiempo accidental, cedemos el poder de nuestra existencia a las máquinas. La velocidad del tiempo accidental no es la velocidad de la reflexión y el debate político. Es una velocidad que solo corresponde a la máquina. Los mensajes políticos que publicamos en Twitter y que compartimos brevemente con la comunidad digital no reflejan nuestras preocupaciones y demandas políticas, sino los momentos de nuestras vidas y nuestra inspiración fugaz.

Así, si nuestro querido Sergio se movía mediando entre el pesimismo de Han (2014a, 2014b) y el optimismo de un Castells (2012), nosotros nos afanábamos por convencerlo de que la única salida del pesimismo, en nuestro caso virilliano, era el normativismo habermasiano.

\section{El acontecimiento mediático y el surgimiento de la teogonía mediática}

En esta línea de argumentación, a Sergio le interesó sobremanera el concepto de acontecimiento. Se trata de algo, vinculado al descubrimiento y 
re-descubrimiento, en lo que Sergio trabajó a fondo (Roncallo-Dow y Mazorra-Correa, 2015; Roncallo-Dow, Córdoba-Hernández y Durán-Camero, 2019) y que se enlaza con nuestras discusiones sobre las transformaciones que generan los espacios públicos digitales y sus efectos, para nosotros un horizonte ideal y normativo de la comunicación, y para él un espacio de hibridación mediática. El acontecimiento es, así, clave, porque nos permite medir lo inmediato y efímero de la comunicación digital versus la esperanza de patrones de resistencia mesurada y reflexiva.

Sergio, junto con otro de nuestros más queridos amigos, Diego Mazorra-Correa, retoman las ideas de Deleuze para enfrentarlas al contexto actual, tomando como caso de estudio la caricatura de Aylan Kurdi, publicada en 2015 por el semanario francés Charlie Hebdo. Y es que hasta allá nos llevaba Sergio a preguntarnos: ¿qué pasaría si lleváramos esas nociones posmodernas que Deleuze había aplicado al orden de la filosofía, la ciencia, la historia o el arte al ecosistema de los medios digitales?

Siguiendo el análisis de Ordóñez-Díaz (2011), el acontecimiento, según Deleuze, se distingue, ante todo, porque su aparición se produce siempre por contraste con un ruido de fondo, eso que podemos denominar con Mitchell (2011) simples "ocurrencias". En ese telón caótico e indiscernible, emerge el acontecimiento: un hecho singular que introduce un orden, un principio de clasificación, una secuencia, un punto de referencia por el que ingresamos en el universo del sentido. Para Deleuze, existen diferentes tipos de acontecimiento como los conceptos en filosofía, los eventos históricos en la historia, las teorías científicas en el mundo científico o los bloques de sensación si hablamos de las artes.

Como argumentara Badiou (1999), los acontecimientos son impredecibles e improductibles, pero una vez suceden, tienen efectos de cambio sobre lo real. El acontecimiento sirve para modelar el presente y el futuro, a la vez que produce formas otras de subjetividad, esto es, "los acontecimientos producen una especie de 'cesar' de las formas mismas de lo real, para abrir campo a lo posible, a lo otro" (Roncallo-Dow et al., 2019, p. 123). 
Pasemos, pues, a la aplicación del concepto a los medios, concretamente a los digitales. Según Deleuze (1989), el acontecimiento funciona bajo la forma de un vector de modelación. Muchas veces, por la avalancha informativa:

Los medios de comunicación sobrecargan nuestro entorno perceptivo y nos llenan de múltiples estímulos a los cuales reaccionamos (en un sentido medianamente hipodérmico) de maneras más o menos activas. El hambre, la guerra, la muerte, se cosifican de forma tal que entran en el régimen cotidiano de circulación semiótica y provocan una suerte de anestésica colectiva [...] que induce un efecto de adormecimiento - una suerte de variación de la hoy clásica disfunción narcotizante [...] - y una extraña sensación de actividad con la pura recepción del hecho mismo. (Roncallo-Dow y Mazorra-Correa, 2015, p. 122)

En medio de ese mundo de ocurrencias en que se convierte la información, emerge inesperadamente un acontecimiento mediático que destaca, se tematiza y, sobre todo, reorganiza el fondo sobre el que aparece. Este hecho aparentemente sin precedentes trae consecuencias en cómo se percibe la realidad. Siguiendo a Valdettaro (2015), la potencia performática de los acontecimientos es siempre diversa y está determinada por la recepción que tiene al instaurarse en la audiencia (Roncallo-Dow y MazorraCorrea, 2015).

Para ilustrar estas ideas, Roncallo-Dow y Mazorra-Correa (2015) escogieron como acontecimiento mediático la fotografía de Aylan Kurdi, el niño sirio de tres años que murió ahogado en la costa de Kos, Turquía, el 2 de septiembre de 2015, mientras buscaba llegar a Europa con su familia. En medio de un caos informativo que se arrastraba desde hacía meses, la crisis migratoria europea, en ese momento, era simplemente un cúmulo de hechos que generaban ruido, pero de un alcance "inimaginable", opacada constantemente por otras informaciones. La triste realidad de miles y miles de personas en el mar Egeo y las costas del Mediterráneo solo dejó de ser una "ocurrencia", para convertirse en una realidad objetiva y cercana, gracias al acontecimiento mediático de la fotografía. Por un momento, los refugiados sirios dejaron de ser números y se convirtieron en personas. Aylan personificó la realidad de tantos niños sometidos a toda clase de peligros por huir de la guerra. 
La imagen de Aylan, fotografiada por la turca Nilüfer Demir, como todo acontecimiento, irrumpió en la vida cotidiana y alteró los mecanismos usuales de comprensión. No en vano, decimos con Sergio, que se trata de un hecho que hace realidad lo inimaginable, que da voz a lo que no podía ser dicho y vida a lo que está más allá de cualquier intento de representación. Por eso, el efecto inmediato del acontecimiento es el shock; no se puede comprender que algo así suceda.

De antemano, el acontecimiento es inimaginable, esquivo. Parece que el lenguaje no es suficiente para describir lo que sucedió. La complejidad del acontecimiento crece cada minuto y la falta de comprensión crece con él. El acontecimiento es lo que se resiste a ser incorporado de la misma manera que incorporamos hechos comunes; lo que escapa de cualquier intento de comprensión. Las imágenes parecen ser un intento de oponerse a este carácter inimaginable del evento. (Roncallo-Dow et al., 2019, p. 123)

Gracias al comportamiento de la foto del niño sirio, Roncallo-Dow y Mazorra-Correa (2015) exponen con claridad las características de un acontecimiento mediático de primer orden. Para los autores, el acontecimiento en internet pasa por dos transformaciones: su reproductibilidad, entendida como el cambio que sufre al reproducirse una y otra vez en un ambiente de consumo masivo de imágenes (Butler, 2007); y el uso que se da a la imagen, sobre todo desde el encuadre del humor, la crítica política y la indignación (Shifman, 2007).

Al mismo tiempo, Roncallo-Dow y Mazorra-Correa (2015) coinciden con algunas ideas de Han (2014a) en su explicación de la shitstorm y la indignación en las redes sociales. El acontecimiento mediático es, ante todo, efímero y nos remite "a una organización de lo real que pasa por la velocidad de la circulación de las imágenes y por un efecto que llamaremos sísmico (para evidenciar su carácter violento e inesperado) que se modela desde la recepción" (p. 127) y, por tanto, desde la reacción de la audiencia.

Finalmente, del acontecimiento mediático se puede decir que es sísmico, porque irrumpe en la vida diaria y disloca los mecanismos de entendimiento. Para Mitchell (2011), es el lugar donde fallan las palabras y las imágenes, sin posibilidad inicial de comprensión, de ahí la necesidad 
de multiplicar y repetir una y otra vez las imágenes. Esto fue lo que pasó en la mañana del 11-S de 2001: veíamos una y otra vez la caída de las Torres Gemelas en Nueva York intentando denodadamente comprender lo incomprensible, imaginar lo in-imaginable. Aunque desde otras perspectivas, algo similar ocurrió con la imagen de Aylan que yacía sin vida en la playa. Según Valdettaro (2015), el niño despliega una narrativa en la que se instala un espacio ambivalente. Por una parte, para las propias masas migrantes, Aylan se torna heroico y un emblema identificatorio, en una dimensión de sentido performático-publicitario en tanto ícono global de sus demandas. Por otra, para los bienpensantes occidentales, las cruentas imágenes del niño instalan una cadena de deudas con la propia especie, manifestada, en ocasiones, como responsabilidad, y en otras, directamente, como culpa (p. 1147).

Es ahí cuando, según Roncallo-Dow y Mazorra-Correa (2015), nos topamos con el componente clave de la shitstorm de Han, el de la narcosis activa, una suerte de necesidad de reproducción de la imagen que nos despierta del letargo. Esa misma narcosis será la que logre suspender el acontecimiento en un presente que se prolongará lo que dure la shitstorm, sin mucho lugar a la demora contemplativa, para dar paso a nuevas imágenes que pasarán de manera fugaz por la retina sin lograr captar una atención duradera (Han, 2014a), hasta que surja un nuevo acontecimiento, y así sucesivamente.

En un trabajo posterior, Sergio tuvo oportunidad de comprobar estos postulados en el trabajo "Aylan Kurdi, Twitter y la indignación efímera" (Roncallo-Dow et al., 2019). El objetivo al estudiar el fenómeno de Aylan y la indignación efímera en Twitter era comprobar el ciclo que venimos explicando. La crisis migratoria era un cúmulo de hechos invisibles para la opinión pública, una suerte de ruido de fondo, de simples ocurrencias que impedían dimensionar la crisis migratoria europea de mediados de 2015. Estos hechos encontraron la posibilidad de hacerse visibles a través de un ícono, un acontecimiento mediático llamado Aylan Kurdi. Con la foto del niño en la playa, se desencadenó una shitstorm (Han, 2014a), que degeneró en una "anestésica colectiva" (Buck-Morss, 2005), un adormecimiento colectivo con pérdida de sensibilidad frente a la crisis migratoria, que duró 
el tiempo que se mantuvo vivo en la agenda de las redes para dar paso de nuevo a unos hechos que se pierden en la invisibilidad, de la que solo logran salir si aparece un segundo acontecimiento, con el que vuelva a comenzar el ciclo, o un acontecimiento de segundo orden que se ancle en el primero.

En ese trabajo, Sergio encontró la forma de avanzar un poco en la tesis de la "anestésica colectiva" de Buck-Morss (2005) y ponerla en diálogo con Han (2014a). De la primera, reconoció que, en efecto, hay una narcosis colectiva producida por el sensorium mediático, pero vio que se presenta hoy de un modo más activo: bajo la forma de la shitstorm del segundo: lo que vemos a diario en las causas globales de indignación en las redes sociales que se mueven a la velocidad del hashtag (Roncallo-Dow et al., 2019).

Hay que reconocer que esta tesis es francamente demoledora, y cuando la tratamos en alguna conversación, generó un ambiente de tristeza y pesimismo. No solo por la constatación de que los medios producen eso que Sergio recogió como "anestésica colectiva", sino también porque todo lo que va unida a ella representa el fin de algo que para muchos es un valor en claro retroceso comunicativo. Esto es, la esperanza de una comunicación política que retomara las promesas de la publicidad burguesa y la hiciera más inclusiva y horizontal. Algo que se transformó en una esperanza para muchos de los que vimos aparecer las redes sociales como un canal de comunicación que hiciera posible desintermediar o puentear a los agentes que tradicionalmente monopolizaban el espacio público y que hacían de él un escenario difuso y fracturado de episodios efímeros y estratégicamente diseñados para confundir cuando no adormecer la opinión pública que, de suyo, debería ser crítica y activa.

\section{A modo de breve conclusión}

A un excéntrico, es decir, a un genio cuyo centro es otro. A una persona que ve la vida y el mundo desde un lugar maravillosamente desviado de la "normalidad", estoy seguro de que le encantaría leer una conclusión para una aportación en un homenaje a su memoria que, en tono jocoso y desenfadado, cantara: "sorpresas te da la vida, la vida te da sorpresas". Eso ha sido para nosotros Sergio. Una auténtica y constante sorpresa que nos ha dado 
la vida. Su forma de afrontar las relaciones humanas, sus trabajos, su look, su enfermedad, sus textos, etc. Todo en él nos parecía una extraordinaria sorpresa. Naturalmente, si uno no es un ingrato, debe estar agradecido a la vida por regalarle maravillosas sorpresas.

Sin embargo, y en un ejercicio de tremenda sinceridad, como merece este homenaje, diré que con él siempre me sentí como ese compañero de vida de Mozart, Antonio Salieri. Para algunos, un magnífico músico, pero cuya obra era consecuencia de la constancia, el tedio y la perseverancia. Mientras, para Mozart, el genio y, a veces, el arrebato era más que suficiente para ofrecer una melodía que se convirtiera en un clásico. Así me parecía mi relación con Sergio. Una relación entre un temperamento genial y un carácter forjado en el acero de un trabajador industrial.

Sin embargo, y a pesar de esto, nunca me achanté y me enfrenté a largos y sesudos debates académicos con Sergio, como los que aquí recogemos, sin el más mínimo complejo. No le dije nunca, no obstante, que, más que discutir con él, yo disimulaba para que no se diera mucha cuenta de que lo que hacía era aprender.

\section{Referencias}

Badiou, A. (1999). El ser y el acontecimiento. Manantial.

Buck-Morss, S. (2005). Walter Benjamin, escritor revolucionario. Interzona.

Butler, J. (2007). Torture and the ethics of photography. Environment and Planning D: Society and Space, 25(6), 951-966. https://doi. org/10.1068/d2506jb

Castells, M. (2012). Redes de indignación y esperanza. Alianza.

Deleuze, G. (1989). Lógica del sentido. Paidós.

Habermas. J. (2010). Teoría de la acción comunicativa. Trotta. 
Hague, B. N. \& Loader, B. D. (Eds.). (1999). Digital democracy: Discourse and decision making in the information age. Routledge.

Han, B.-C. (2014a). En el enjambre. Herder.

Han, B.-C. (2014b). Razionalità digitale e la fine dell'agire comunicativo. goWare.

Lazarsfeld, P. y Merton, R. (1948). Comunicación de masas, gustos populares y acción social organizada. En M. de Moragas (Ed.), Sociología de la comunicación de masas. Vol. 2: Estructura, funciones y efectos. (pp. 22-49). Gustavo Gili.

Mitchell, W. J. (2011). Cloning terror: The war of images, 9/11 to the present. University of Chicago Press.

Ordóñez-Díaz, L. (2011). Arte y acontecimiento: una aproximación a la estética deleuziana. Revista Latinoamericana de Filosofía, 37(1), 127-152. http://www.academia.edu/download/33663198/ Arte_y_acontecimiento._Una_aproximacion_a_la_estetica_ deleuziana.pdf

Roncallo-Dow, S. (2015). Muchedumbre, artes y política: Byung-Chul Han y las racionalidades comunicativas contemporáneas. Palabra Clave, 18(2), 305-311. https://doi.org/10.5294/pacla.2015.18.2.1

Roncallo-Dow, S. y Mazorra-Correa, D. (2015). Aylan Kurdi, Charlie Hebdo y el acontecimiento. Discursos Fotográficos, 11(19), 119-146. https://doi.org/10.5433/1984-7939.2015v11n19p119

Roncallo-Dow, S., Córdoba-Hernández, A. M.y Durán-Camero, M. (2019). Aylan Kurdi, Twitter y la indignación efímera. Reis: Revista Española de Investigaciones Sociológicas, 165, 121-142. https://doi. org/10.5477/ cis/reis.165.121 
Shifman, L. (2007). Humor in the age of digital reproduction: Continuity and change in internet-based comic texts. International Journal of Communication, 1, 187-209. https://ijoc.org/index.php/ijoc/ article/view/11/34

Scolari, C. (2014, diciembre 21). Byung-Chul Han: ¿filosofía para Dummies? (II). https://hipermediaciones.com/2014/12/21/byungchul-han-filosofia-para-dummies-ii/

Valdettaro, S. (2015). Mediatización: hacia una ecología performática de los restos y la deriva. Palabra Clave, 18(4), 1128-1154. https:// doi.org/10.5294/pacla.2015.18.4.8

Virilio, P. (1986). Speed and politics: An essay on dromology. MIT Press. https://mitpress.mit.edu/books/speed-politics 